\title{
Pragmatismo, Halloween, Comitê de Aula, Ciclismo e Covid-19: Tudo Junto e Misturado!
}

\section{Vanessa Regina Ostrowski ${ }^{1}$, Luiz Fernando Nieuwenhoff Schefer ${ }^{2}$, Marcia Strapazzon ${ }^{2}$, Monica Cristina Rovaris ${ }^{3}$ e Ruan Carlos dos Santos ${ }^{4}$}

${ }^{1}$ Programa de Pós-graduação em Administração da Universidade do Estado de Santa Catarina, Brasil | vr.ostrowski@gmail.com | https://orcid.org/0000-0002-3652-5031

${ }_{2}^{2}$ Pós-graduação em Administração da Universidade Federal de Santa Catarina, Brasil | fernandoschefer@gmail.com; marcia.macasarin@gmail.com | https://orcid.org/00000002-4232-026X | https://orcid.org/0000-0001-8884-423X

${ }^{3}$ Departamento de Administração, Universidade Federal de Sergipe, Brasil | monicarovarisdoutorado@gmail.com | https://orcid.org/0000-0001-9294-3935

${ }^{4}$ Centro Universitário UNIAVAN, Brasil | ruan_santos1984@hotmail.com | https://orcid.org/0000-0001-7396-8774

\begin{abstract}
Resumo: Este caso descreve uma experiência de apresentação de um trabalho sobre pragmatismo e sociologia pragmática, na modalidade aula EAD e de forma não presencial, realizada por alunos de doutorado, em programa de pós-graduação em Florianópolis, em tempos de pandemia. A disciplina de Epistemologia da Ciência da Administração teve carga horária de 60 horas, e foi realizada entre os meses de agosto a dezembro de 2020. Procurou ainda, discutir os aprendizados decorrentes de tal experiência ao discutir o pragmatismo e a sociologia pragmática; a dialética e 0 paradigma crítico e círculo das matrizes epistemológicas de Paula (2015); bem como as possibilidades de utilização de tais aprendizados, em experiências futuras, podendo ser utilizado nas disciplinas de epistemologia dos estudos organizacionais; pesquisa avançada; pesquisa qualitativa; entre outras. O levantamento foi realizado por meio de observação participante e entrevistas. Também foram utilizados vídeos, notícias publicadas na imprensa local, bem como os textos da disciplina de Epistemologia da Ciência da Administração.
\end{abstract}

Palavras-chave: Aulas EAD; Pragmatismo; Sociologia Pragmática; COVID-19.

Pragmatism, Halloween, Class Committee, Cycling and Covid-19: All Together and Mixed!

Abstract: This case describes an experience of presenting a work on pragmatism and pragmatic sociology, in the EAD class modality and in a non-presential way, carried out by $\mathrm{PhD}$ students, in a postgraduate program in Florianopolis, in times of pandemic. The subject of Epistemology of Science of Administration had a workload of 60 hours, and was held between the months of August to December 2020. It also sought to discuss the learnings arising from such experience by discussing pragmatism and pragmatic sociology; the dialectics and critical paradigm and circle of Paula's epistemological matrices (2015); as well as the possibilities of using such experiences of theory in practice and, in future experiences, can be used in the disciplines of epistemology of organizational studies; advanced research; qualitative research; among others. The survey was conducted through participant observation and interviews. Also used were videos, news published in the local press, as well as the texts of the discipline of Epistemology of Science of Administration.

Keywords: EAD Classes; Pragmatism; Pragmatic Sociology; COVID-19.

\section{Introdução}

Desde 2020 passamos a conviver e discutir com mais intensidade os significados e implicações de palavras como COVID-19, Coronavírus, pandemia, trabalho remoto, fazendo-nos refletir sobre a forma como entender o saber, a ciência e a epistemologia. A partir do dia 11 de março de 2020, quando foi declarado pela Organização Mundial da Saúde (OMS) como pandemia, o vírus da COVID-19 já causou até março 2021, a contaminação de mais de 116 milhões de pessoas e a morte de mais de 2,5 milhões de pessoas pelo mundo (UNIVERSIDADE JOHNS HOPKINS, 2021). No mesmo período, o Brasil possuía mais de 10,8 milhões de casos confirmados e mais de 262 mil pessoas haviam perdido a vida (BRASIL, 2020). 
No começo da pandemia estávamos tendo aula presencial no doutorado em Administração, devido ao contexto as aulas começaram a ser realizadas em ambiente virtual. Em breve teríamos que apresentar um trabalho sobre o pragmatismo. O que fazer? Como conciliar a criatividade do agir, as dinâmicas sociais, o foco nas práticas tão caras ao pragmatismo (Andion et al., 2017) sem o desenvolvimento de uma dinâmica com a turma? O pragmatismo reconhece a incerteza, o caráter provisório das situações, valoriza a experimentação social (Berk et al., 2012). Nada mais coerente com a temática pragmatista que experimentar uma solução hibrida, onde teríamos a aula online, mas também faríamos a turma experenciar o aprendizado. Neste cenário, a pergunta de pesquisa é: Como os alunos doutorandos, por meio de processo criativo, desenvolveram o processo de ensino- aprendizagem no semestre 2020/1, durante a pandemia COVID$19 ?$

Para o desenvolvimento do tema em sala recomendamos aos colegas que assistissem a dois documentários: (1) Consultório da Rua - A rua não é um mundo fora do nosso mundo e (2) Situações de Rua; o intuito destes documentários era demonstrar como há necessidade de estar junto à situação, experenciando para compreendê-la de fato. É apenas em frente as situações problemáticas que os pesquisadores podem compreender os atores, como agem, o que sentem e porque falam o que falam (Cefaï, 2017). Os vídeos em conjunto com os textos recomendados pela professora da disciplina já deveriam demonstrar a diferença da epistemologia pragmatista para as demais epistemologias estudadas até aquele momento.

Contudo, ainda ansiávamos pela experiência prática. Esta foi pensada e desenvolvida com intuito de despertar nos doutorandos interesse no debate e fixação do conteúdo lido para a aula. Na perspectiva de realizar uma reflexão sobre a produção do saber e do campo científico, o presente trabalho tem como objeto de descrever os desafios enfrentados pelos alunos de um programa de doutorado, para a apresentação de um trabalho de pragmatismo e sociologia pragmática, de forma não presencial, em tempos de pandemia. Foram discutidos os aprendizados decorrentes de tal experiência, bem como as possibilidades de utilização de tais aprendizados.

As fontes dos dados da origem e evolução histórica dessa aula da Universidade, bem como das personalidades envolvidas no caso foram obtidas por meio das páginas de revista e reportagem de circulação estadual (tais como Jornal Catarinense, Notícias do Dia da NSC, CORREIO SC, Vídeos do YOUTUBE entre outras) matéria de revistas de grande circulação e website da Universidade e organizações sociais em questão. Os dados apresentados no caso e os desdobramentos foram reais e obtidos de fontes secundárias, por meio de reportagens em revistas, páginas da internet, Políticas, Estatuto e Regimentos da disciplina de Epistemologia da Universidade via EAD. Incluiu-se como principais fontes de informação para construção da história, os testemunhos dos alunos da Universidade e da professora da disciplina.

\section{Antecedentes e Origem da História}

Ao refletir sobre a melhor forma de apresentar um trabalho sobre o pragmatismo e a sociologia pragmática em um curso de pós-graduação, por meio de uma plataforma não presencial, mas, online, em temos de pandemia, tivemos a oportunidade de revisitar os textos de Corrêa (2014), Dewey (1938), Timmermans e Tavory (2012) e Barthe et al. (2016) a respeito de pragmatismo nas ciências sociais, bem como contar a experiência de desenvolvimento de um comitê de aula desta temática. Fomos os responsáveis doutorandos Cristiano, Regina e outros colegas de pesquisa - para desenvolver um Comitê de aula na disciplina Epistemologia da Ciência em Administração em uma Universidade Pública de Santa Catarina.

Também tivemos a oportunidade de assistir a uma live sobre Endowments e Fundos, pois Cristiano, um dos doutorandos, tinha interesse em compreender os fundos patrimoniais em sua tese. Em uma das falas da live lembrou muito do utilitarismo e do positivismo, do cálculo racional e da observação do que pode ser avaliado. 
Uma das palestrantes, ao falar das estratégias de mobilização de recursos para os fundos patrimoniais, relatou a entrega de cofres para crianças utilizarem no Halloween, como estratégia de fidelização de um futuro doador, que poderia ser o potencial doador de amanhã, o que potencialmente contribui para doações futuras. Isso fez Cristiano lembrar da morte e em todo o esforço que estava sendo feito, em tempos de pandemia, que para evitá-la no curto prazo, seja em razão de COVID-19, seja, por exemplo, pela fome, que voltou a preocupar muitas pessoas. Lembrou da doação de cestas básicas para as pessoas atingidas pela covid19, de comunidades de periferia da Grande Florianópolis, que tinham medo de passar fome. Ficou pensando que não era possível só observar aquilo que era passível de ser avaliado e, que os valores eram importantes, já que os valores se apresentavam nas consequências. Pensou que o pragmatismo poderia nos ajudar a ir além.

O pragmatismo é uma contribuição filosófica originária dos Estados Unidos cuja origem pode ser atribuída a Charles Sanders Peirce (1839-1914), William James (1841-1910), John Dewey (1859-1952) e George Hebert Mead (1863-1931). O termo deriva da mesma palavra grega prágma, que significa ação, do qual vêm as nossas palavras "prática" e "prático" (Pierci, 1883). Os pragmatistas clássicos, ao refletirem sobre as consequências práticas e de como funciona ou pode-se realizar a ação do que as pessoas fazem, procuram superar os dualismos metafísicos como, por exemplo, empirismo versus racionalismo, realidade versus aparência, corpo versus mente e sujeito versus objeto, já que não há separação entre o campo das ideias e a nossa capacidade de mudar o mundo. Como colocado por Pierci (1883) "a significação intelectual das ideias está inteiramente contida nas conclusões que podem delas ser tiradas e em última instância nos efeitos que elas têm sobre nossa conduta" (Cometti, 2010, P. 59).

Com o intuito de superar a dicotomia e separação entre o empirismo e racionalismo (temas já vistos na disciplina), procura desenvolver a noção de experiência, de forma a torná-lo mais amplo e mais próximo da noção de acompanhar e refletir sobre o homem vivendo, já que o conhecimento não poderia ser meramente especulativo, centra-se nas atividades práticas em situação, que não são estabelecidas com antecedências, mas, são moduladas durante as intervenções e interações. Não é a experiência que é experienciada, e sim a natureza - pedras, plantas, animais, doenças, saúde, temperatura, eletricidade, e assim por diante. A experiência é da, tanto quanto, em a natureza. Coisas interagindo de determinadas maneiras são a experiência, já que elas são aquilo que é experienciado (Dewey, 1974). Ligadas de determinadas outras maneiras com outro objeto natural -o organismo humano -, elas são, ademais, como as coisas são experienciadas. Portanto, a experiência avança para dentro da natureza; tem profundidade. É também dotada de largura indefinidamente elástica, pois o homem não é, portanto, visto como o "sabe tudo" ou um ser com uma vocação transcendental, mas antes, um organismo que se desenvolveu num contínuo processo de amadurecimento de seus esquemas biológicos, sociais, históricos, por meio de interações e experimentações, e retoma a necessidade de tomar cuidado com os priori, com comportamentos pré-definidos, a experiencia, modificando-se de forma reciproca, portanto, não separa a natureza da experiência (Dewey, 1974).

Ao tentar pôr fim às querelas filosóficas intermináveis da metafísica e das disputas indução versus dedução, Pierce (1883) opta pela criação da lógica da abdução. Timmermans e Tavory (2012) têm a possibilidade de refletir sobre a forma como a lógica abdutiva, em conexão com as nossas questões atuais, pode ser aplicada nas ciências sociais, observando quais as diferenças com relação à dedução e indução. Para estes autores, a abdução não é a simples soma da dedução e indução, mas, contém os dois momentos, já que não os deixa de lado. Há, portanto, um encontro em vários pontos da dedução e da indução, trabalhando com vários tipos de conceitos e de forma plural, já que as "certezas" são vistas como provisórias. Portanto, mais do que discutir os conceitos de um problema, é possível discutir os temas que o envolvem ao se olhar para os fenômenos, sendo tal questão conduzida de antigos para novos insights teóricos. Como colocado ainda pelos autores, "o problema não era tanto chegar a uma boa hipótese, mas decidir qual hipótese valia a pena perseguir: como escolheríamos uma direção particular dentro de um universo infinito de possibilidades" (Timmermans e Tavory, 2012, p. 36). 
Resgatando os conceitos trazidos do pragmatismo clássico, as perspectivas pragmatistas da capacidade crítica, dos momentos de prova (Latour, 2012) e da análise processual dos dispositivos, Barthe et al. (2016), tratam do rótulo "sociologia pragmática" ou "sociologia das provas" como um estilo que implica fortes convergências, mas não uma perfeita homogeneidade de todos os trabalhos que o reivindicam. Do mesmo modo, embora seja reconhecido por um conjunto de traços distintivos, bem identificáveis, ele apresenta um grau evidente de variabilidade, mas, também, de desacordo ou de conflito. Existem vários pragmatismos. Apesar de não haver uma homogeneidade dos trabalhos rotulados sob esse título, em Barthe et al. (2016) são apresentados como principais aportes teóricos de referência de seu arcabouço: a antropologia das ciências e das técnicas, desenvolvida por Michel Callon e Bruno Latour, e a sociologia dos regimes de ação, praticada por Luc Boltansky e Laurent Thévenot. (Barthe et al., 2016).

As situações de prova constituem-se em momentos de incerteza, no qual as possibilidades de mudança dependem do fluxo da ação, situações nas quais os sujeitos precisam provar suas competências (Boltansky \& Thévenot, 1999; Chateauraynaud, 2017). Corrêa (2014) destaca que a sociologia pragmática francesa advoga a importância das situações problemáticas e das incertezas como modalidades que permitem a captação do social, revelando progressivamente o social como problema, em oposição a ideia fundacional durkheimiano de observar os fatos sociais como coisa, havendo a "passagem do problema do social para o social como problema (Corrêa, 2014, p. 40). Essas situações de prova geram a possibilidade de olhar as controvérsias, quem são seus porta-vozes, como dizem, como se comportam, como pode ser criada uma estabilização, como isso pode ser rompido, sendo possível ter contraponto, ter uma pluralidade e não só uma única voz. Conforme sintetizado por Magalhães; Andion e Alperstedt (2020, p. 685) situação de prova é uma "situação que surge de um incômodo, de uma consequência percebida, que provoca perguntas e que, portanto, leva ao exame, ao debate e à investigação".

A partir da leitura e revisitação dos textos, ao pensar na elaboração do comitê de aula, a primeira questão que emergiu era como poderíamos incentivar uma reflexão densa dos colegas e refletir sobre a importância da descrição das situações, dos momentos de prova, das controvérsias, conectando o micro e o macro, pensando além da dedução e da indução, sem ir para a ação? Como poderíamos apresentar um trabalho de pragmatismo sem permitir que os colegas experimentem essa ação, já que as experiências acontecem nas situações? Como poderíamos experienciar essa ação sem sair de casa? Como experienciar efeitos e consequências práticas de uma ação? Como trazer o pragmatismo para a vida cotidiana? Uma outra questão era que não conhecíamos a maioria dos colegas da turma. $\mathrm{Na}$ verdade, nunca nos tínhamos visto pessoalmente, todas as aulas foram online. Éramos amigos virtuais? Iríamos julgá-los pela aparência vista pela câmera do meu computador, no conforto de casa? Como ficaríamos com os nossos a priori? Seriam a priori virtuais? Como acompanharíamos os atores em tempos de pandemia? Como veríamos a diversidade de uma turma tão plural? Eles não poderiam nos dizer uma coisa, por meio daquela câmera, mas ir lá e fazer outra nos momentos de tensão e contradições? Isso nos gerava uma grande inquietação.

\section{Metodologia}

A elaboração do comitê de aula ocorreu na disciplina de Epistemologia da Ciência em Administração no curso de Doutorado de uma universidade pública do estado de Santa Catarina. A disciplina objetiva demonstrar aos doutorandos a evolução da epistemologia no campo da administração no decorrer do tempo. A disciplina foi cursada por sete doutorandos, cinco mulheres e dois homens. Além da professora havia um monitor de turma do sexo masculino. A idade média dos doutorandos é de 33 anos. $O$ objetivo do comitê era ensinar a epistemologia pragmatista contribuindo para o conhecimento teóricoprático dos doutorandos.

A pandemia transformou a realidade dos estudantes de todo o mundo, para os estudantes desta disciplina não seria diferente. Estávamos com aulas online o que dificulta a execução de dinâmicas de grupo. 
Entretanto, não víamos como seria possível ensinar pragmatismo sem uma experiência prática. $\mathrm{O}$ pragmatismo confere um verdadeiro estatuto epistêmico às experiências e aos diferentes artifícios empregados para ligá-las aos processos coletivos (Frega, 2019). Com intuito de incitar a participação dos colegas e desenvolver uma dinâmica mesmo com os obstáculos impostos pela pandemia dividimos o comitê de aula em quatro etapas (1) leitura dos artigos; (2) assistir os vídeos; (3) montagem dos artefatos e (4) discussão das três etapas.

A leitura dos artigos recomentados pela professora foram de Corrêa (2014), Dewey (1938), Timmermans e Tavory (2012) e Barthe et al. (2016). Com base nestes autores os doutorandos compreenderiam o Pragmatismo na teoria. Para transformar a teoria em algo mais palpável recomendamos aos colegas que assistissem a dois documentários: (1) Consultório da Rua - A rua não é um mundo fora do nosso mundo e (2) Situações de Rua; os documentários somados aos textos almejavam demonstrar aos colegas um pressuposto importante e central ao pragmatismo. Em situações problemáticas os atores agem de forma diversa dos seus quadros de referência, eles sentem, se ressentem e moldam o campo de experiência (Cefaï, 2017).

A montagem dos artefatos o jogo de cordas e o tangram consolidariam o conhecimento dos colegas por meio da experiência. Sabíamos que cada doutorando montaria seus artefatos de forma diferente, pois há uma infinidade de possibilidades a serem desenvolvidas fazendo com que a subjetividade de cada um possa emergir. O objetivo desta demonstração foi demonstrar a construção de futuros possíveis. Este constructo de futuros possíveis trabalha a questão da subjetividade que influencia e é influenciada pelo meio, os futuros são construídos pelos atores com base em suas experiências, histórias e trajetórias (Chateauraynaud, 2017).

A quarta e última etapa foi realizada de forma online; houve um debate acalorado a respeito da importância da experiência e em como era possível observar a interação no humano e do não-humano em nosso cotidiano, entretanto pouco prestávamos atenção neste fenômeno que ficou evidente com os artefatos. Ficou demonstrado que a realidade é fluida, instável, indeterminada e quando os atores experimentam essa indeterminação eles tem força de mudar (Dewey, 1939). Este conceito, ficou bastante evidente pela forma como desenvolvemos a dinâmica. Entregar os artefatos de bicicleta em diversos pontos da cidade exigiu dos doutorandos uma vontade de mudar a realidade que estava colocada.

\section{A Experiência}

Pensando em possibilitar aos colegas a experimentação incorporada e reflexiva e um processo de interação (Cefaï, 2003; Cefaï, 2006) pensamos na elaboração de alguns desafios práticos, feitos de materiais de madeira, que pudessem ser manuseados pelos colegas, durante a leitura dos textos. Nesse sentido foram elaborados dois dispositivos: o artefato de cordas, feito de material reciclado (figura 1), e um Tangram ${ }^{1}$ com um kit ${ }^{2}$ para artesanato, cada qual com suas respectivas instruções, como mostram as figuras 1 e 2 .

\footnotetext{
${ }^{1}$ É um quebra-cabeças geométrico chinês formado por sete peças, chamadas tans: dois triângulos grandes, dois pequenos, um médio, um quadrado e um paralelogramo. Utilizando todas essas peças sem sobrepôlas, podem ser formadas várias figuras. Segundo a Enciclopédia do "Tangram" é possível montar mais de 5000 figuras.

${ }^{2}$ Quatro varetas de madeira; uma lixa; um pincel e dois frascos com tinta guache.
} 


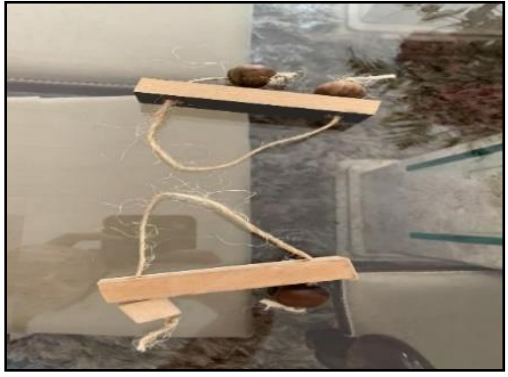

Fig. 1. Jogo de Cordas

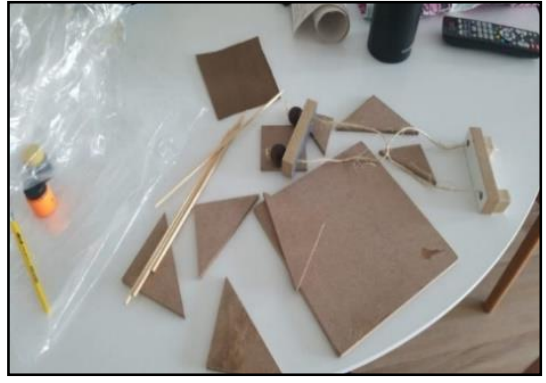

Fig. 2. Modelo de Tangram

Fonte: Elaborado pelos autores (2020).

Para auxiliar os atores no processo de experiência, foram elaboradas algumas instruções, como mostra a tabela 1.

Tabela 1. Instruções do desafio

\begin{tabular}{|c|c|}
\hline Artefato de cordas & Tangram \\
\hline $\begin{array}{l}\text { Oi. Eu sou um não humano! Disseram- } \\
\text { me que sou um conjunto de partes e } \\
\text { que essas são chamadas pelos } \\
\text { humanos de "lixo" e que seriam } \\
\text { jogadas fora. Não entendi o que é } \\
\text { "jogar fora" já que somos todos de um } \\
\text { mesmo planeta. Você me acha um lixo } \\
\text { também? Você poderia me ajudar? Eu } \\
\text { sou um conjunto de partes e gosto } \\
\text { muito disso. Porém, gostaria de saber } \\
\text { o que é poder ser livre dessa minha } \\
\text { segunda parte. Você poderia me ajudar } \\
\text { a me separar dessas "amarras" e me } \\
\text { permitir ser duas partes de mim? Mas, } \\
\text { cuidado. Não corte o fio condutor que } \\
\text { nos une. Pense, reflita. Dê voltas. Olhe } \\
\text { para além da aparência. Não procure o } \\
\text { consenso, mas as contradições. Mas, } \\
\text { não desista de experimentar e tentar. } \\
\text { Caso tenha dificuldades, um conselho: } \\
\text { se associe, peça ajuda. Porém, quando } \\
\text { conseguir, você terá um outro desafio. } \\
\text { Sou um conjunto de partes. Separar- } \\
\text { me pode te ajudar a entender o meu } \\
\text { problema, mas depois de me separar, } \\
\text { por favor, me uma oportunidade } \\
\text { novamente. Promete? Depois que } \\
\text { aprendi a me associar, entendi que não } \\
\text { poderia viver sem a minha outra parte. } \\
\text { Posso contar com você? Um abraço de } \\
\text { um não humano que era "lixo", mas, } \\
\text { acredita que ainda podemos ir além. }\end{array}$ & $\begin{array}{l}\text { Que tal a gente sair do } \\
\text { quadrado? Ajuda-me? } \\
\text { Por onde começamos? } \\
\text { Induzir, deduzir, } \\
\text { abduzir? Positivismo, } \\
\text { funcionalismo, } \\
\text { dialética, sistemismo, } \\
\text { construtivismo? É um } \\
\text { triângulo, um quadrado } \\
\text { ou um losango? Que } \\
\text { tal pintarmos? Pode } \\
\text { colar, cortar, lixar e } \\
\text { transformar. Pode } \\
\text { misturar. Pode perder } \\
\text { a paciência, desistir e } \\
\text { tentar de novo. Pode } \\
\text { pedir ajuda. Pode rir, } \\
\text { chorar ou rezar. Pode } \\
\text { ver as situações, os } \\
\text { contextos e o } \\
\text { ambiente. Pode ser } \\
\text { humano e não } \\
\text { humano. Pode não ter } \\
\text { a solução e pode ainda } \\
\text { tentar uma inovação. } \\
\text { O que é sair do } \\
\text { quadrado para você? } \\
\text { Compartilha comigo? } \\
\text { Vamos experienciar? }\end{array}$ \\
\hline
\end{tabular}

Fonte: Elaborado pelos autores (2020).

Ao elaborar os jogos, os autores preocuparam-se em relação à entrega de tais produtos, de forma segura, em razão da pandemia do Covid-19. 
No período, o Brasil possuía mais de 5 milhões de casos confirmados e mais de 150 mil pessoas haviam perdido a vida (BRASIL, 2020). Na TV diziam que não deveriam sair de casa.

Na casa de Cristiano, sua esposa tinha muito medo de que ele saísse de casa, pois tinham parentes que possuíam problemas respiratórios e eram considerados integrantes de grupos de risco. Por outro lado, Cristiano tinha muita vontade de sair de casa. A opinião das pessoas que ele amava interferia nas suas decisões frente a esse dilema de sair ou ficar em casa. No trabalho, acabamos optando pela entrega dos produtos, na casa das pessoas, de bicicleta. Nesse sentido fizemos o levantamento dos endereços dos colegas da turma.

Para realizar as entregas, optamos pela elaboração de uma faixa que fizesse menção a alguns elementos trazidos nos textos. Colocamos então nosso plano em prática, conseguimos realizar as entregas, percebemos que não planejamos a demora nas entregas, pois cada entrega era muito mais demorada do que havíamos planejado. Os colegas queriam conversar, trocar experiências, já abriam os pacotes que estavam cuidadosamente embalados e eram higienizados a cada entrega. Cada entrega foi uma surpresa no sentido de conhecer cada colega, pois estávamos no final do semestre e não havíamos nos encontrado pessoalmente.

Mesmo antes da aula já recebíamos depoimentos de como os desafios estavam interferindo na rotina dos colegas, bem com as fotos do resultado do desafio nas figuras 3 e 4.

Relato da experiência da Marciane:

"No dia 12 de outubro de 2020, quando tocou o interfone em casa foi uma festa só. As crianças já esperam ansiosas 'os correios' porque pode ser uma entrega pra elas. E naquele dia realmente era. Uma surpresa e tanto! Uma caixa enorme, com um avião e uma motocicleta de madeira, uma torre de Hanoi, tintas e pincéis, e um artefato. Dois pedaços de madeira ligados por um 'nó' de corda. Nas instruções dizia que devíamos separar as partes. As crianças se ocuparam das novidades, foram pintar as peças da torre de Hanoi e eu me concentrei no artefato. Me pré-considerando não criativa, aquilo ia levar décadas... Tentei por uns 40 minutos e convidei meu filho de 9 anos a ajudar. $O$ bichinho se distraiu por um tempo e logo desistiu. $O$ artefato ficou por ali... Fiquei de olho pra ver se meu marido (conhecido por sua criatividade) iria pegá-lo. Naquele dia não rolou. Eu tentei mais um pouco. E então meu filho propôs uma grande ideia: procurar na internet! Se seguiu uma mega discussão sobre trapacear. Ele dizia que não, argumentando que ele era impaciente, a lua em áries (maldito o dia que soltei essa pérola). Eu insistia que era desonesto, que certamente uma hora conseguiríamos (confesso que quase cedi mais tarde, mas o senso de responsabilidade com a educação das crianças foi mais forte que minha impaciência - graças!). E assim foram passando os dias... Eventualmente alguém pegava o artefato e dava umas voltas pelas madeiras, uns nós pelas cordas, na esperança de, milagrosamente, as peças se soltarem. Nenhum movimento do marido, que consistentemente se sentava na cadeira mais próxima da TV assistindo futebol. $O$ artefato não tinha lugar certo nos primeiros dias. Uns quinze dias depois o armário que sustenta a TV foi eleito seu espaço. Eu e as crianças fomos sublimando a necessidade de resolver o quebra cabeça, nos distraindo com o dia a dia. Finalmente, no primeiro dia do feriadão, o marido, em silêncio, sem alardes, pega o artefato, manipula e começa a mexer nas cordas. Todos pararam para olhar. Ele foi empurrando a cordinha por dentro do buraquinho por que ela passava. E assim as peças se separaram! Fizemos festa e indagamos como tinha chegado nessa hipótese. Ao que ele responde: muitos anos de barqueiro, muitos nós... Na sequência todos experimentaram a sensação de separar e juntar, separar e juntar. Agora estamos todos craques no quebra cabeça, cuja solução agora nos parece tão óbvia..." (Figura 4). 


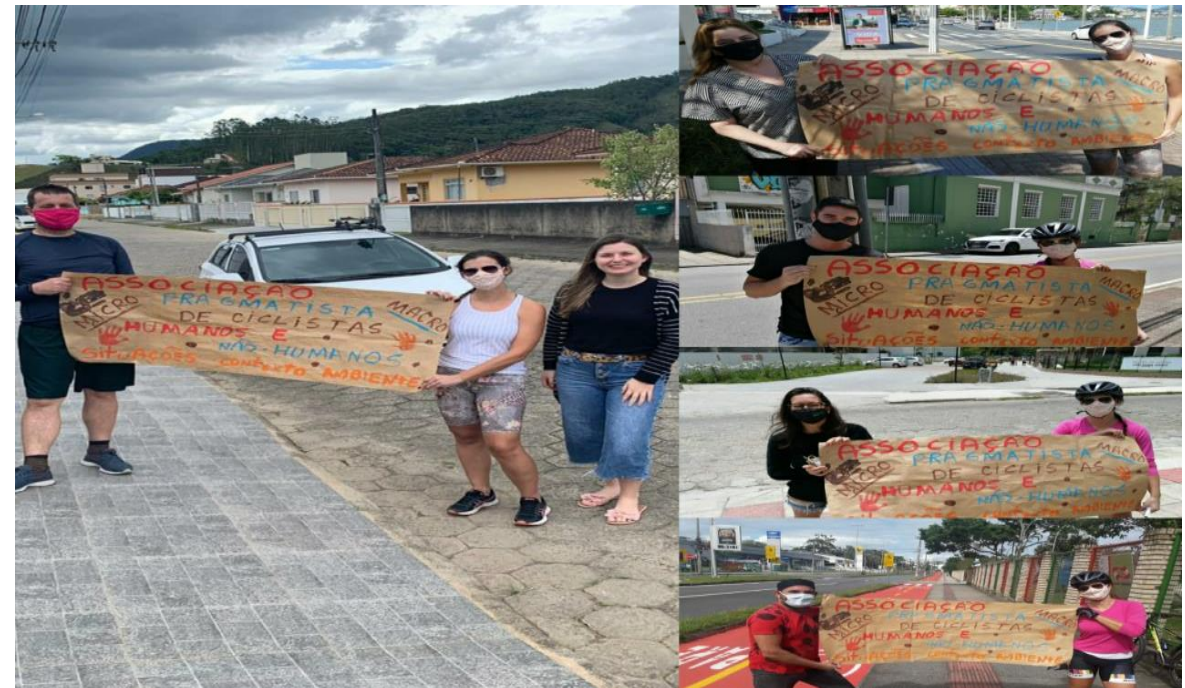

Fig. 3. Entrega dos materiais para os alunos da turma
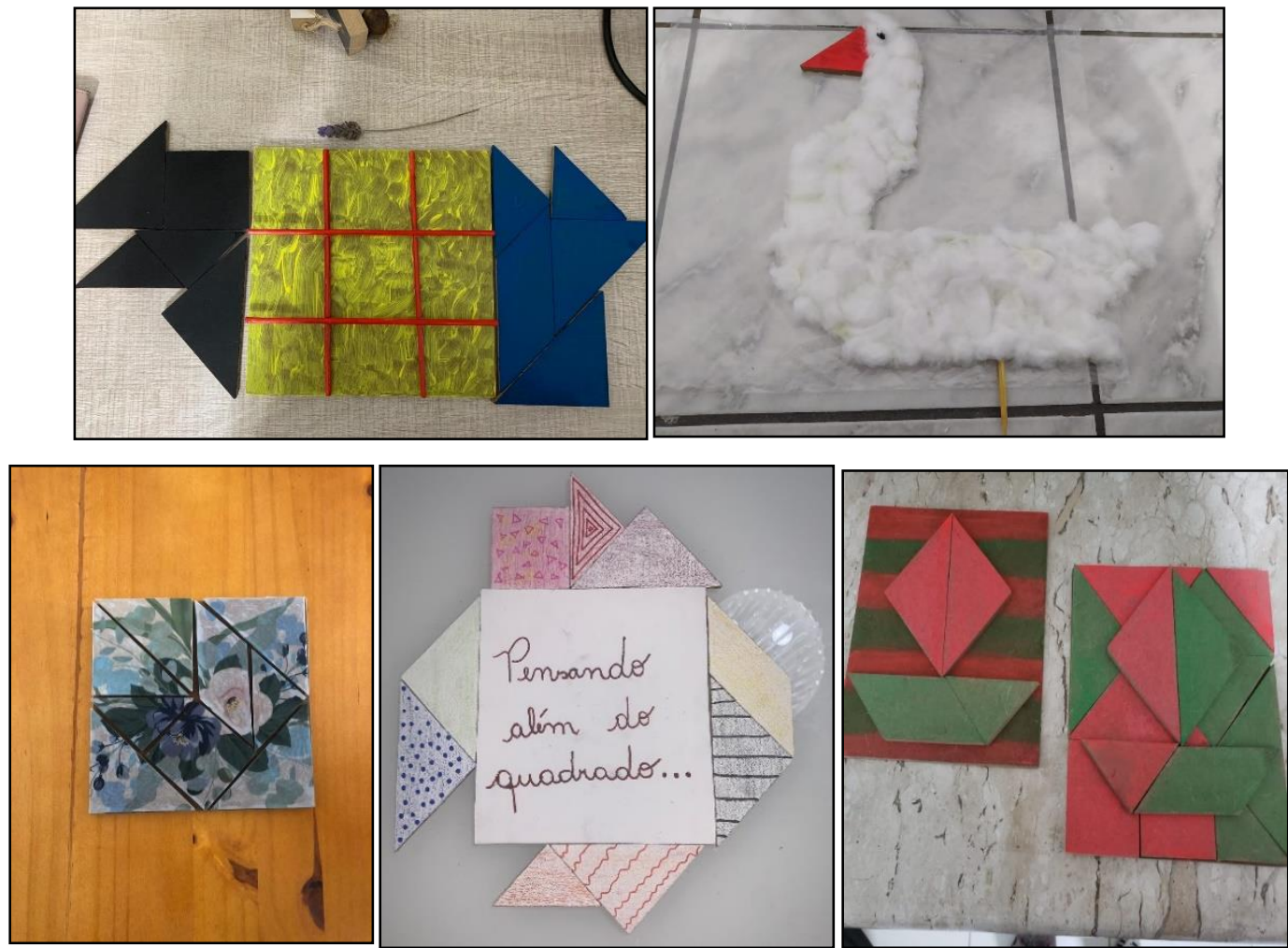

Fig. 4. Imagens dos trabalhos realizados pelos doutorandos

Fonte: Imagem registrada pelos autores (2020).

A epistemologia pragmatismo se interessa principalmente nos significado e destaca 0 papel dos símbolos na mediação da vida social (Berk et al., 2012). As pessoas agem com base no significado que as coisas tem para si, esse significado pode mudar de acordo com a interação social e o meio (Dewey, 1998). Esses pressupostos pragmatistas ficaram demonstrados na singularidade de cada tangram. Na forma particular que cada doutorando narrou a experiência com os artefatos. 


\section{Considerações Finais: $O$ que aprendemos com a experiencia em tempos de pandemia?}

Os autores nunca tinham tido a oportunidade de fazer uma disciplina de epistemologia dos estudos organizacionais na graduação ou no mestrado. Além disso, havia o desafio de realizar a disciplina de forma remota, bem como de apresentar trabalhos. Era uma experiência nova para todos. Após finalizar a disciplina no doutorado, observamos que isso fez muita falta em nossa formação acadêmica. O único modelo que conhecemos nas disciplinas de metodologia que cursamos na graduação, foi o modelo de Burrell e Morgan (1979). De começo, nos foi avisado que precisaríamos escolher um dos "quadrados" e que eles eram "excludentes" entre si. Precisávamos ser eficientes, eficazes e efetivos na graduação e quando estivéssemos trabalhando em uma empresa.

No curso de economia, Cristiano aprendeu que deveria ser um pesquisador neutro que podia maximizar a minha utilidade e que possuía uma racionalidade plena que me possibilitava tomar decisões certeiras que me tornariam mais feliz.

Diante de tantos desafios ao longo da experiência para os envolvidos, como pensar fora da caixa? Como colocado por Paula (2015), ao apresentar a tese da incompletude cognitiva, não é possível atingir todo o conhecimento, apenas parte dele. Nesse sentido, as abordagens sociológicas são antes aproximações que não abarcam toda a verdade e realidade que existe no mundo e precisam ser usadas e vistas de forma complementar e dinâmica, em um trabalho de "escavação" do conhecimento e de recombinações, levando a novas teorias e metodologias.

Um dos aprendizados foi que convivemos nesse ano com a pandemia e os estragos que isso ainda terá sobre a vida das pessoas, precisamos ter cada vez mais um posicionamento crítico que nos permita pensar para além das verdades absolutas. Uma atitude que dói, já que nos tira da nossa zona de conforto e que coloca em xeque as nossas certezas e verdades absolutas, outrora vistas como imutáveis.

Um conjunto de situações que passa por um processo de escavação, repensando os estudos organizacionais e possibilitando, como colocado por Caitano e Serva (2020) e por Paula (2015, p. 15) "a criação e aprimoramento de teorias e metodologias, evidenciando o caráter dinâmico da produção do conhecimento sociológico". Afinal, como ficar indiferente em momentos de pandemia?

Neste sentido, acreditamos que novas pesquisas que discutam formas de desenvolver conteúdos teóricos em contexto de pandemia devam ser realizados. Mesmo que voltemos ao contexto de aulas presenciais estas experiências podem ser uteis para melhorar o ensino aprendizagem. Novas formas de engajar estudantes em debates mais calorosos de forma criativa só enriquecem as práticas educacionais.

A partir da leitura dos textos e das reflexões feitas durante a disciplina, nos faz destacar alguns elementos do que aprendemos e que levaremos para a formulação da tese e para a vida enquanto estudantes, pais, filhos e cidadãos:

- Experimentar, por meio de um processo de interação, uma experiência incorporada e reflexiva, já que o principal meio de pesquisa etnográfica é a experiência corporificada do pesquisador (Cefai, 2003; Cefai, 2006)

- Aceitar a pluralidade dos sujeitos que fazem parte de uma arena pública;

- Se associar com outros sujeitos na discussão dos problemas;

- Preocupar-se com a contextualização das situações por meio de uma boa descrição das situações, do contexto e do ambiente, sendo possível sentir e vivenciar lugares e momentos, mostrar as ações e interações, como se estivéssemos presentes (Cefai, 2014, p. 16);

- Conectar o micro (reflexão sobre a experiência vivenciada especificamente pelos agentes), o meso (observação e análise das ações na organização) e o macro (análise dos momentos críticos do contexto, buscando pontos de comparação ampliar e aprofundar o campo de pesquisa, em não projetar indevidamente categorias e hipóteses exógenas sobre os dados de campo) (Cefai, 2014); 
- Entender o sujeito como protagonista na pesquisa que é realizada e não como uma coisa e/ou como um objeto de pesquisa;

- Observar um problema a partir das contradições e não do consenso;

- Resgatar a paixão de estar com os atores no campo;

- Ser capaz de se comunicar com as pessoas que estão vivendo as experiências e problemas do dia a dia;

- Engajar as pessoas para que discutam e publiquem os seus problemas, trazendo os problemas para o público;

- Engajar os problemas reais a partir do que acontece na realidade.

E assim seguimos na pesquisa....

\section{Referências}

Andion, C., Ronconi, L., Moraes, R. L., Ribeiro Gonsalves, A. K., Serafim, D., \& Brum, L. (2017). Civil society and social innovation in the public sphere: a pragmatic perspective. RAP: Revista Brasileira de Administração Pública, 51(3).

Barthe, Y.; Rémy, C.; Trom, D.; Linhardt, D.; De Blic, D.; Heurtin, J. P.; Lagneau, É.; De Bellaing, C. M.; Lemieux, C.(2016). Sociologia Pragmática. Guia Do Usuário. Sociologias, Porto Alegre, 18(41), pp. 84-129.

Berk, G., Deutschmann, C., Quack, S., Schneiberg, M., \& Ansell, C. (2012). On Christopher K. Ansell Pragmatist Democracy: Evolutionary Learning as Public Philosophy. Oxford/New York, NY, Oxford University Press, 2011. Socio-Economic Review, 10(3), 581-604.

Boltansky, L; Thévenot, L. (1999). The sociology of critical capacity European Journal of Social Theory 2(3), 1999, p.359-377.

Brasil. Painel CoronaVírus. 2020. Recuperado em 18 Jan. 2021 de https://covid.saude.gov.br/.

Burrell, G.; Morgan, G. (1979). Sociological paradigms and the organisational analysis. London: Ashgate, (Capítulos 8 a 11).

Caitano, D.; Serva, M. (2020, nov) No limite da razão: o deliberar e a phrónesis no trabalho prisional. Cad. EBAPE.BR, v. 18, Edição Especial.

Caitano, D. (2016). As situações críticas de gestão no trabalho dos agentes no complexo penitenciário do estado de Santa Catarina (COPE) e a tensão no deliberar. Tese Doutorado UFSC, Florianópolis, Brasil.

Cefai, D. Pasquier, Dominique. "Les Sens du public". In: (Orgs.). Les Sens du public: publics politiques, publics médiatiques. Paris: PUF, 2003. pp. 13-59.

Cefaï, Daniel; Quéré, Louis. “Naturalité et socialité du Self et de l'esprit”. In: Mead, George. L'Esprit, le soi et la société.Paris: PUF, 2006. pp. 3-90.

Cefaï, D. (2007). Porquoi se mobilise-t-on? Les théories de l'action collective. Paris: Éditions La Découverte.

Cefai, D. (2013) ¿Qué es la etnografía? Debates contemporáneos. Arraigamientos, operaciones y experiencias del trabajo de campo. Primera parte. Persona y sociedad, 27(1), pp. 101-119.

Cefai, D. (2013) ¿Qué es la etnografía? Segunda parte. Inscripciones, extensiones y recepciones del trabajo de campo. Persona Y Sociedad, 27(3), pp. 11-32, 2013.

Cefai, D. (2010). Provações corporais: uma etnografia fenomenológica do atendimento de urgência aos moradores de rua. Lua Nova, 79(1), pp. 71-110.

Cefai, D. (2017) Públicos, problemas públicos, arenas públicas. O que nos ensina o pragmatismo (Parte II). Novos estudos. CEBRAP, 36(2), p. 129-142.

Cefai, D. (2017) Públicos, problemas públicos, arenas públicas. O que nos ensina o pragmatismo (Parte I). Novos estudos. CEBRAP, 36(1), pp. 187-213. 
Chateauraynaud, F. (2017). A CAPTURA COMO EXPERIÊNCIA: Investigações pragmáticas e teorias do poder. Revista Brasileira de Ciências Sociais, 32(95), 01. https://doi.org/10.17666/329504/2017

Cometti, Jean-P. (2010). Qu'est-ce que le pragmatisme? Gallimard: Paris, p. 10-59.

Corrêa, D. (2014). Do Problema do social ao social como problema: elementos para uma leitura da sociologia pragmática francesa. Revista de Ciências Sociais, n. 40, Abril de 2014, pp. 35-62

Dewey, J.(1938). Investigação Social. In: DEWEY, J. Lógica. Teoria de la investigación. Mexico: Fondo de Cultura Economica.

Dewey, J. (1939). Democracia criativa: a tarefa diante de nós. Democracia Cooperativa: Escritos Políticos de John Dewey (2)1927-1939), 135-152.

Dewey, J. (1974) Experiência e natureza; Lógica: a teoria da investigação; A arte como experiência; Vida e educação; Teoria da vida moral. São Paulo: Abril.

Dewey, J. (1998). The essential Dewey: Pragmatism, education, democracy (Vol. 1). Indiana University Press.

Frega, R. (2019). Pragmatism and the Wide View of Democracy. In Pragmatism and the Wide View of Democracy. https://doi.org/10.1007/978-3-030-18561-9

GIFE. $11^{\circ}$ Congresso do GIFE: Fronteiras da ação coletiva. Recuperado em https://congressogife.org.br/2020/palestra/endowments-e-fundos-patrimoniais. de 20 Dez. 2020.

Koyré, A. (2011). As origens da ciência moderna: uma nova interpretação. In: KOYRÉ, A. Estudos de História do Pensamento Científico. Rio de janeiro: Forense Universitária.

Latour, B. (2012). Reagregando o Social. Uma Introdução à Teoria do Ator-Rede. Salvador: EDUFBA.

Magalhães, T.; Andion, C.; Alperstedt, G. (2020) Laboratórios vivos de inovação social e ação pública: um enfoque analítico e um caminho metodológico baseado no pragmatismo. Cad. EBAPE.BR, v. 18, Edição Especial, Rio de Janeiro.

Paula, A. P.(2015) Repensando os estudos organizacionais: para uma nova teoria do conhecimento. São Paulo: Editora FGV.

Peirce, C. (1983) Escritos coligidos. Tradução de Armando Mora D"Oliveira e Sérgio Pomerangblum. $3^{a}$ ed. São Paulo: Abril Cultural, 1983, p. 8. (Coleção Os Pensadores).

Timmermans, S.; Tavory, I. (2012) Theory Construction in Qualitative Research: From Grounded Theory to Abductive Analysis. Sociological Theory, 30(3), pp. 167-186.

UJH. Universidade Johns Hopkins. New Cases of Covid-19 in World Countries. 2020. Recuperado em https://coronavirus.jhu.edu/data/new-cases de 20 Dez. 2020. 